\title{
Binary Tree Pricing to Convertible Bonds with Credit Risk under Stochastic Interest Rates
}

\author{
Jianbo Huang, ${ }^{1}$ Jian Liu, ${ }^{2}$ and Yulei Rao' \\ ${ }^{1}$ School of Business, Central South University, Changsha, Hunan 410083, China \\ ${ }^{2}$ School of Economics \& Management, Changsha University of Science \& Technology, Changsha 410004, China
}

Correspondence should be addressed to Yulei Rao; yuleirao@sina.com

Received 18 January 2013; Accepted 21 March 2013

Academic Editor: Chuangxia Huang

Copyright (C) 2013 Jianbo Huang et al. This is an open access article distributed under the Creative Commons Attribution License, which permits unrestricted use, distribution, and reproduction in any medium, provided the original work is properly cited.

The convertible bonds usually have multiple additional provisions that make their pricing problem more difficult than straight bonds and options. This paper uses the binary tree method to model the finance market. As the underlying stock prices and the interest rates are important to the convertible bonds, we describe their dynamic processes by different binary tree. Moreover, we consider the influence of the credit risks on the convertible bonds that is described by the default rate and the recovery rate; then the two-factor binary tree model involving the credit risk is established. On the basis of the theoretical analysis, we make numerical simulation and get the pricing results when the stock prices are CRR model and the interest rates follow the constant volatility and the time-varying volatility, respectively. This model can be extended to other financial derivative instruments.

\section{Introduction}

Convertible bonds with the characteristic of bonds and stock are a complex financial derivative. They provide the right to holders that they give up the future dividend to obtain some stock with specified quantity. The pricing of convertible bonds is more difficult than straight bonds and options; the main reason is that it not only has value of bonds, but also involves all kinds of embedded option value brought by provisions of conversion, call, put, and so on. What is more, the embedded options in most times are American options. So, generally speaking, the pricing of convertible bonds cannot get closed-form solution; in most conditions, numerical method was adopted, for example, binary tree method, Monte Carlo method, finite difference method, and so on. As for Monte Carlo method, firstly it uses different stochastic differential equations to describe the pricing factor models in the market for simulation, then it makes pricing based on the characteristic of convertible bonds, for example, the boundary conditions acquired by all kinds of provisions, to make pricing for conversion bonds (Ammann et al. [1], Guzhva et al. [2], Kimura and Shinohara [3], Yang et al. [4], and Siddiqi [5]). But because the supposed parameters of stochastic differential equations are exogenous, this method not necessarily makes a better fitting for the existing market conditions. The binary tree method can solve the above problems.

The binary tree method is firstly put forward by Cox et al. [6], Cox-Ross-Rubinstein (CRR) binomial option pricing model. After that, many researchers revised and popularized it. Cheung and Nelken [7] firstly apply binary tree to convertible bonds pricing and obtain the pricing solution of a twofactor model which is based on stock prices and interest rates. Carayannopoulos and Kalimipalli [8] apply the trigeminal tree pricing model to convertible bonds pricing research with single factor. Hung and Wang [9] also apply binary tree model to convertible bonds pricing which embodies default risk and considers the influences of stock prices and interest rates. Chambers and $\mathrm{Lu} \mathrm{[10]} \mathrm{further} \mathrm{considered} \mathrm{the} \mathrm{correlation} \mathrm{of}$ stock prices and interest rates and expanded the model of Hung and Wang. Binary tree model has been widely used in the pricing of contingent claims such as stock options, currency options, stock index options, and future options. Xu [11] proposes a trinomial lattice model to price convertible bonds and asset swaps with market risk and counterparty risk. 
Interest rate is a very important factor in the financial market; all security prices and yields are related to it. The interest rates model has equilibrium model, no-arbitrage model, and so on. In the equilibrium model, interest rates are generally described by some stochastic process, which is mean-reversion, to make interest rates show the trend of convergence to a long-term average with the passing of time, including Vasicek model, Rendleman-Bartter model, and CIR model. The parameters of these models should be estimated with history data, by selecting parameters purposely, but generally this fitting is not accurate and even reasonable fitting formula cannot be found. No-arbitrage models make initial term structure as model input and construct a binary tree such as CRR model for interest rate process, so that the term structure can fit the reality better and more concise. The relatively wide application no-arbitrage models include Holee model, Hull-White model, Black-Derman-Toy model, and Heath-Jarrow-Morton model. Different from the interest rate model of Hung and Wang and Chambers and Lu, this paper uses constant volatility and time-varying volatility binary tree model to describe short interest rates which are more intuitive and convenient.

This paper makes pricing research of convertible bonds with the call and put provisions and uses binary tree method for the modeling of state variables in the financial market. As the duration of convertible bonds is relatively longer than straight bonds, their prices are subject to the impact of interest rates. Moreover, as one of the corporate bonds, convertible bonds may have credit risk. So this paper uses different binary trees to model the process of stock prices and interest rates, and considering the impact of stock dividends and credit risk to convertible bonds, it adopts default rate and recovery rate to describe credit risk and get two-factor binary tree model involving credit risk; on this basis, with example simulation to get the convertible bonds, pricing results under the condition of stock price obey CRR model, constant volatility interest rate binary tree model, and timevarying volatility interest rate binary tree model.

\section{Market Model}

\subsection{Interest Rates Binary Tree}

2.1.1. Constant Volatility Binary Tree Model. Ritchken [12] deduces the continuous form of short-term $r(t)$ in HoLee model [13] meeting the following stochastic differential equations:

$$
d r(t)=\mu(t) d t+\sigma(t) d z(t), \quad t>0
$$

where $\mu(t)$ is the drift, $\sigma(t)$ is the instantaneous volatility, both can be the function of time $t$, and $z(t)$ is Brownian motion.

Grant and Vora [14] get the discrete form of (1) as follows:

$$
\Delta r(t)=\mu(t) \Delta t+\sigma(t) \Delta z(t), \quad t \geq 0 .
$$

Make $f(j)$ to be the forward interest rate in the interval $[j, j+$ 1]. Then get

$$
\begin{gathered}
\mu(0) \Delta t=f(1)-r(0)+\frac{\Delta t}{2} \sigma^{2}(r(1)), \\
\mu(1) \Delta t=f(2)-f(1)+\frac{\Delta t}{2} \sigma^{2}\left(\sum_{j=1}^{2} r(j)\right)-\Delta t \cdot \sigma^{2}(r(1)), \\
\mu(t-1) \Delta t=f(t)-f(t-1)+\frac{\Delta t}{2} \sigma^{2}\left(\sum_{j=1}^{t} r(j)\right) \\
-\Delta t \cdot \sigma^{2}\left(\sum_{j=1}^{t-1} r(j)\right)+\frac{\Delta t}{2} \sum_{n=1}^{t-2} \sigma^{2}\left(\sum_{j=1}^{n} r(j)\right), \quad \forall t \geq 3, \\
\sum_{n=0}^{t} \mu(n) \Delta t=f(t+1)-r(0)+\sum_{n=1}^{t} \delta(n), \quad \forall t \geq 1,
\end{gathered}
$$

where

$$
\begin{aligned}
& \sum_{n=0}^{t} \delta(n)=\frac{\Delta t}{2} \sigma^{2}\left(\sum_{j=1}^{t+1} r(j)\right)-\frac{\Delta t}{2} \sigma^{2}\left(\sum_{j=1}^{t} r(j)\right), \\
& \forall t \geq 1, \\
& \sigma^{2}\left(\sum_{j=1}^{t} r(j)\right)=\sigma^{2}\left(\sum_{j=1}^{t}(t-j+1) \sigma_{j-1} \Delta z_{j-1}\right) \\
&=\sum_{j=1}^{t}(t-j+1)^{2} \sigma_{j-1}^{2} \Delta t .
\end{aligned}
$$

Suppose that volatility is constant; that is, $\sigma(t)=\sigma_{c}, \forall t>$ 0 , and then

$$
\begin{aligned}
\sigma^{2}\left(\sum_{j=1}^{t} r(j)\right) & =\sigma^{2}\left(\sum_{j=1}^{t}(t-j+1) \sigma_{c} \Delta z_{j-1}\right) \\
& =\sigma_{c}^{2} \sum_{j=1}^{t}(t-j+1)^{2} \Delta t .
\end{aligned}
$$

And get the constant volatility interest rates binary tree as shown in Figure 1.

2.1.2. Time Varying Volatility Binary Tree Model. Jarrow and Turnbull [15] supposed that the volatility of short-term is changeable in different intervals, but is constant in the same time interval. Let $\Delta t=1$, and then the discrete form of interest rates can meet

$$
r(t)=r(0)+\sum_{j=0}^{t-1} \mu(j)+\sigma(t-1) \sum_{j=0}^{t-1} \Delta z(j) .
$$




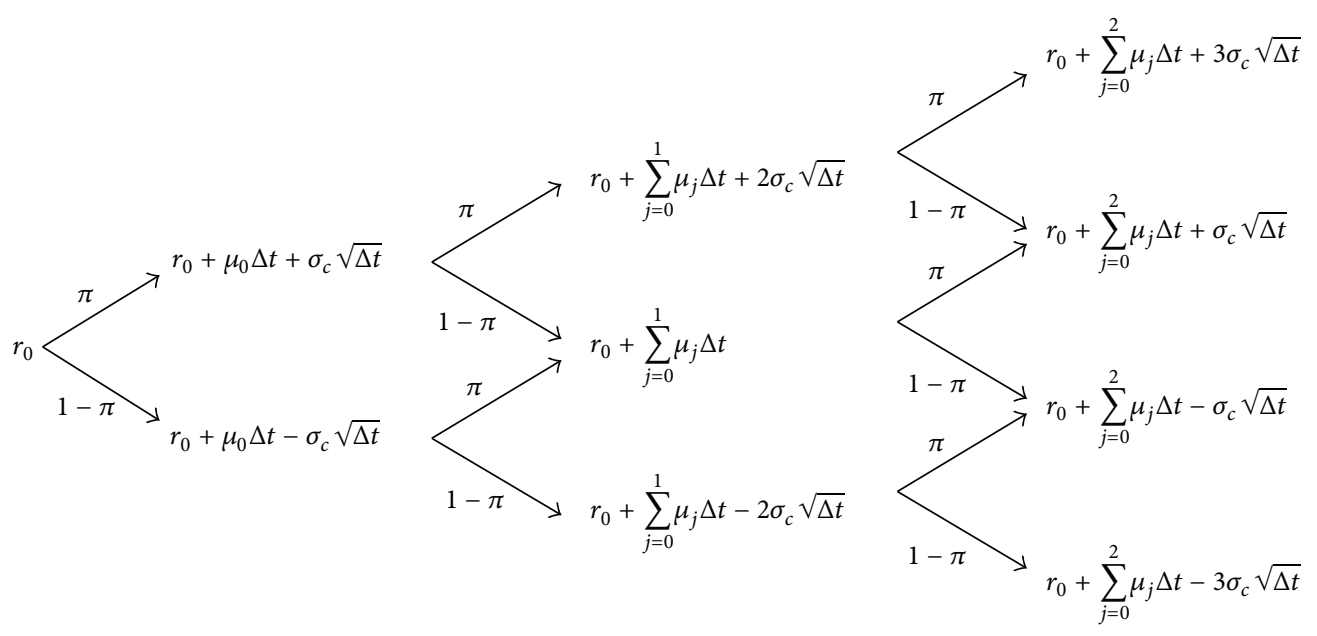

FIGURE 1: 4-period constant volatility interest rates binary tree.

The variance formula of the sum of short-term interest rate is

$$
\sigma^{2}\left(\sum_{j=1}^{t} r_{j}\right)=\sum_{j=0}^{t-1}(j+1) \sigma_{j}^{2}+\sum_{j=0}^{t-2} \sum_{k=j+1}^{t-1} 2(j+1) \sigma_{j} \sigma_{k} .
$$

And then get time-varying interest rates tree as shown in Figure 2.

2.2. Stock Price Binary Tree. Suppose that the current moment is 0 and the expiration date of convertible bonds is $T$. According to interval $\Delta t$, we divide the period $[0, T]$ to $L$ subintervals: $\left[t_{i}, t_{i+1}\right], 0 \leq i \leq L, t_{0}=0, t_{L}=T, T=L \Delta t$. In each interval $\left[t_{i}, t_{i+1}\right]$, there are two possible states in the market, up or down. The change of every market state is independent. $\mathrm{U}$ means the up state and $\mathrm{D}$ means the down state.

The stock prices will have two states; $p$ means the probability of market up, and then the probability of market down is $1-p$. If the current stock price is $S$, then the stock price of later period may have two possibilities: $S_{u}, S_{d}$, and $S_{u}=S \times u, S_{d}=S \times d ; u, d$ separately mean the magnitude of up and down. If the initial price of stock is known, then the stock price tree can be determined by the given model parameters $p, u$, and $d$.

Model parameters $p, u$, and $d$ will directly impact the results of binary tree; the selection of them should follow no-arbitrage principle. Generally speaking, there are two selections: CRR model [4], equal-probability binomial model (Roman [16], Hull [17]). This paper adopts CRR model to describe pricing process of stock.

CRR model selects parameters as follows:

$$
\begin{gathered}
u=e^{\sigma_{s} \sqrt{\Delta t}}, \quad d=u^{-1}=e^{-\sigma_{s} \sqrt{\Delta t}}, \\
p=\frac{1}{2}\left[1+\frac{\mu_{s}}{\sigma_{s}} \sqrt{\Delta t}\right] .
\end{gathered}
$$

Especially, if the actual financial market is changed to risk neutral market. Then the expected profit $\mu_{s}$ of stock will change to risk-free interest rate $r$, but the volatility $\sigma_{S}$ is the same. The probability of price up in this model is $p=\left(e^{r \Delta t}-\right.$ $d) /(u-d)$; among them, $r$ is risk-free interest rate. Under this condition, the pricing result is no arbitrage.

2.3. Credit Risk. Consider convertible bonds with credit risk. We adopt the method of Jarrow and Turnbull [18] to model the credit risk of convertible bonds. Suppose that the probability of default risk in time interval $\left[t_{i-1}, t_{i}\right]$ is $\lambda_{i}$ and the rate of recovery is $\xi_{i}$ when default. If there are serials different deadline risk-free zero-coupon bonds in the financial market and the prices are $\{P(1), P(2), P(3), \ldots, P(n)\}$, the serials of different deadline risk company zero-coupon bonds and the prices are $\{D(1), D(2), D(3), \ldots, D(n)\}$. We can get the riskfree interest term structure and risk interest term structure from them. If the recovery rate $\xi_{i}$ is already known, then the rate of risk $\lambda_{i}$, in number $i$ period of bonds, can be acquired. The detail analysis process is as follows.

If the risk-free interest rate of one-year period is $r_{0}$ and risk interest rate is $r_{1}^{*}$, then

$$
e^{-r_{1}^{*}}=\left[1 \cdot\left(1-\lambda_{1}\right)+\xi_{1} \cdot \lambda_{1}\right] e^{-r_{0}} \text {, and get } \lambda_{1}=\frac{1-e^{r_{0}-r_{1}^{*}}}{1-\xi_{1}} \text {. }
$$

If the risk interest rate of two-year period is $r_{2}^{*}$, then

$$
\begin{aligned}
e^{-2 r_{2}^{*}}=\{ & {\left[1\left(1-\lambda_{2}\right)+\xi_{2} \lambda_{2}\right] e^{-r_{u}} \pi\left(1-\lambda_{1}\right) } \\
& +\left[1\left(1-\lambda_{2}\right)+\xi_{2} \lambda_{2}\right] e^{-r_{d}}(1-\pi)\left(1-\lambda_{1}\right) \\
& \left.+\xi_{1} \lambda_{1}\right\} e^{-r_{0}}
\end{aligned}
$$

When $\lambda_{1}, \lambda_{2}$ can be got by the above formula, with the same method, we can get the risk interest rate $\left\{\lambda_{i}, i \geq 1\right\}$ of each period. 


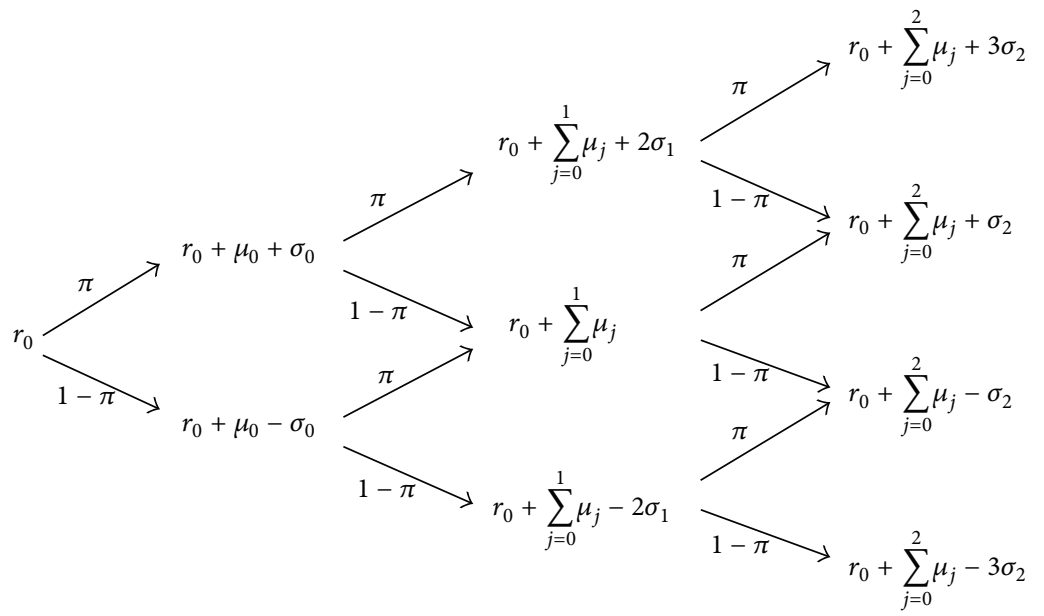

FIGURE 2: 4-period time-varying interest rate tree.

\section{Stock and Interest Rate Binary Tree Model with Credit Risk}

For convertible bonds with credit risk, suppose that the underlying stock price and risk-free interest rate process are random, and the underlying stock price process is described by CRR model, where the stock magnitude of up and down is $u=e^{\sigma_{S} \sqrt{\Delta t}}, d=e^{-\sigma_{S} \sqrt{\Delta t}}$ respectively. Suppose that the stock price is 0 when default, and then the possible price of stock is $0, S_{u}, S_{d}$.

In risk-neutral world, the expected yield rate is risk-free interest rate $r$, and the stock continuous dividends yield is $q$, then the expected yield rate is $r-q$; so to meet the no-arbitrage condition, there is

$$
S e^{(r-q) \Delta t}=p(1-\lambda) S u+(1-p)(1-\lambda) S d+0 \cdot \lambda .
$$

Then get $p=\left(e^{(r-q) \Delta t} /((1-\lambda)-d)\right) /(u-d)$. $p$ is the up probability of stock with credit risk. As the risk-free interest rate of all periods is random, suppose that the risk-free interest rate of number $i$ period is $r_{i}$, the volatility of stock is constant $\sigma_{S}$, and dividends rate is $q_{i}$, so the parameters of stock price in all periods can be generally presented as

$$
\begin{aligned}
& u_{i}=e^{\sigma_{s} \sqrt{\Delta t}}, \quad d_{i}=e^{-\sigma_{S} \sqrt{\Delta t}}, \\
& p_{i}=\frac{e^{\left(r_{i}-q_{i}\right) \Delta t} /\left(1-\lambda_{i}\right)-d}{u-d} .
\end{aligned}
$$

Suppose risk-free interest rates are stochastic and described by binary tree model, then the stock tree and interest rate tree involving credit risk are combined as shown in Figure 3. In this paper, we suppose that the correlation coefficient of interest rate and stock price is 0 .

After obtaining the process of stock prices and risk-free interest rates, the value of convertible bonds can be got by backward induction. We divide the value of convertible bonds into two parts; one is the value of equity got by converting to stock or exercise embedded options; the other is bonds value

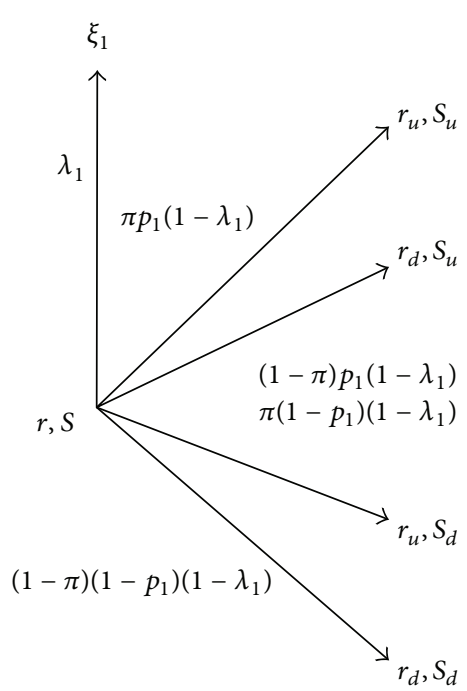

FIGURE 3: 4-period two-factor binary tree with credit risk added.

that is the present value of bonds when repaying capital and interest and the present value of the residual value.

Suppose that the default probability of convertible bonds in the interval $\left[t_{k-1}, t_{k}\right]$ is $\lambda_{k}$, recovery value is $\xi_{k}$, and then the holding value at $t_{k}$ time is $E V_{k}$, given by

$$
E V_{k}=\text { (the expected equity value at } t_{k+1} \text {-time }
$$$$
+ \text { the expected bonds value at }
$$

$$
\left.t_{k+1} \text {-time }\right) \cdot e^{-r_{k} \cdot \Delta t} \text {. }
$$

So the value of convertible value at time- $t_{k}$ is

$$
\begin{array}{r}
V_{k}=\max [\min (\text { the holding value at } \\
\left.t_{k} \text {-time, call value }\right), \\
\text { conversion value, put value }] \\
=\max \left[\min \left(E V_{k}, V_{k}^{\text {call }}\right), V_{k}^{\text {con }}, V_{k}^{\text {put }}\right] .
\end{array}
$$




\section{Numerical Examples}

We take a four-period binary tree model as an example to expound the convertible bonds pricing process with call provision and put provision in the above models and compare the results under the constant volatility interest rate model and the time-varying volatility interest rate model.

4.1. Process of Interest Rate and Stock. The initial parameters of the convertible bond are all the same to the constant volatility interest rate model and the time-varying volatility interest rate model. Suppose that time interval $\Delta t=1$, the up probability of interest rates is $\pi=1 / 2$, and the $1-4$ year period yields of risk-free zero-coupon bonds are $6.145 \%$, $6.366 \%, 6.837 \%$, and $6.953 \%$, respectively; the volatility of short-term interest rates is $2.5 \%$. So the other binary tree parameters of constant volatility interest rate can be got as shown in Table 1 . In the same way, the other binary tree parameters of time-varying volatility interest rate can be got as shown in Table 2. Then we get the two interest rate binary trees.

The process of underlying stock prices uses CRR model to describe. The selected parameters 8 are as follows: $S_{0}=25$, $\sigma_{S}=0.185, \Delta t=1, T=4$, and $q=0.04$. So all the parameters under constant volatility interest rate are

$$
\begin{aligned}
& u=1.2032, \quad d=0.8311, \\
& p_{r_{0}}=0.5887, \quad p_{r(1)_{u}}=0.6841, \\
& \operatorname{Pr}_{r(1)_{d}}=0.5923, \quad \operatorname{Pr}_{r(2)_{u u}}=0.7517, \\
& \operatorname{Pr}_{r(2)_{u d}}=0.6577, \quad \operatorname{pr}_{r(2)_{d d}}=0.5667, \\
& p_{r(3)_{\text {uuu }}}=0.9162, \quad \operatorname{Pr}_{r(3)_{\text {uud }}}=0.8170, \\
& \operatorname{pr}_{r(3)_{u d d}}=0.7209, \quad \operatorname{pr}_{r(3)_{d d d}}=0.6279 .
\end{aligned}
$$

In the same way, the parameters under time-varying volatility interest rate model are

$$
\begin{aligned}
& u=1.2032, \quad d=0.8311, \\
& p_{r_{0}}=0.5887, \quad p_{r(1)_{u}}=0.6826, \\
& \operatorname{pr}_{r(1)_{d}}=0.5908, \quad \operatorname{Pr}_{r(2)_{u u}}=0.7475, \\
& \operatorname{Pr}_{r(2)_{u d}}=0.6594, \quad \operatorname{Pr}_{r(2)_{d d}}=0.5739 \text {, } \\
& p_{r(3)_{\text {uиu }}}=0.8764, \quad p_{r(3)_{\text {uud }}}=0.8027, \\
& \operatorname{pr}_{r(3)_{u d d}}=0.7307, \quad \operatorname{Pr}_{r(3)_{d d d}}=0.6604 .
\end{aligned}
$$

Then we get the four-period stock prices binary tree.

4.2. Default Rates. We take the corporate bonds as reference risk bonds; suppose that the 1-4-year period yields of corporate zero-coupon bonds are 7.645\%, 8.155\%, 8.557\%, and $9.128 \%$, respectively, and the recovery rate of convertible bonds is constant $\xi=45 \%$, and one-year risk-free interest rate $r_{0}=6.145 \%$.
Interest rate binary tree indicates that the branch point of number $n$ period is $n$. If the interest rate of number $i$ branch point in number $n$ period is $r(n-1)_{\omega}, \omega$ is the interest rates state from start to current, and then the derived interest rate branch point of number $n+1$ period is $r(n)_{\omega u}, r(n)_{\omega d}$. As $\pi=$ $1 / 2=1-\pi$, to meet the no-arbitrage principle, parameters $\left\{\lambda_{1}, \lambda_{2}, \lambda_{3}, \lambda_{4}\right\}$ meet the following four equations:

$$
\begin{aligned}
& e^{-r_{1}^{*}+r_{0}}=\left(1-\lambda_{1}\right)+\xi \cdot \lambda_{1}, \\
& e^{-2 r_{2}^{*}+r_{0}}=\pi\left(1-\lambda_{1}\right)\left(1-\lambda_{2}+\xi \lambda_{2}\right) \\
& \times\left(e^{-r(1)_{u}}+e^{-r(1)_{d}}\right)+\xi \lambda_{1}, \\
& e^{-3 r_{3}^{*}+r_{0}}=\pi^{2}\left(1-\lambda_{1}\right)\left(1-\lambda_{2}\right)\left(1-\lambda_{3}+\xi \lambda_{3}\right) \\
& \times\left[e^{-r(1)_{u}}\left(e^{-r(2)_{u u}}+e^{-r(2)_{u d}}\right)\right. \\
& \left.+e^{-r(1)_{d}} \cdot\left(e^{-r(2)_{u d}}+e^{-r(2)_{d d}}\right)\right] \\
& +\pi\left(1-\lambda_{1}\right) \xi \lambda_{2}\left(e^{-r(1)_{u}}+e^{-r(1)_{d}}\right)+\xi \lambda_{1}, \\
& e^{-4 r_{4}^{*}+r_{0}}=\pi^{3}\left(1-\lambda_{1}\right)\left(1-\lambda_{2}\right)\left(1-\lambda_{3}\right)\left(1-\lambda_{4}+\xi \lambda_{4}\right) \\
& \times\left\{e ^ { - r ( 1 ) _ { u } } \left[e^{-r(2)_{u и}}\left(e^{-r(3)_{u u и}}+e^{-r(3)_{u и d}}\right)\right.\right. \\
& \left.+e^{-r(2)_{u d}}\left(e^{-r(3)_{u u d}}+e^{-r(3)_{u d d}}\right)\right] \\
& +e^{-r(1)_{d}}\left[e^{-r(2)_{u d}}\left(e^{-r(3)_{u u d}}+e^{-r(3)_{u d d}}\right)\right. \\
& \left.\left.+e^{-r(2)_{d d}}\left(e^{-r(3)_{u d d}}+e^{-r(3)_{d d d}}\right)\right]\right\} \\
& +\pi^{2}\left(1-\lambda_{1}\right)\left(1-\lambda_{2}\right) \xi \lambda_{3} \\
& \times\left[e^{-r(1)_{u}}\left(e^{-r(2)_{u u}}+e^{-r(2)_{u d}}\right)\right. \\
& \left.+e^{-r(1)_{d}}\left(e^{-r(2)_{u d}}+e^{-r(2)_{d d}}\right)\right] \\
& +\pi\left(1-\lambda_{1}\right) \xi \lambda_{2} \cdot\left(e^{-r(1)_{u}}+e^{-r(1)_{d}}\right)+\xi \lambda_{1} .
\end{aligned}
$$

By the above equations and the constant volatility interest rate binary tree, the default rates of bonds in every period are shown in Table 3.

Similarly, the default rates of corporate bonds in every period under time-varying volatility interest rate binary tree are shown in Table 4.

4.3. Price Process of Convertible Bonds. The convertible bond contains call and put provisions, the duration is $T=4$, the face value got in maturity date is 100 , conversion rate is 3 , callable price is $V_{\text {call }}=106$, and puttable price is $V_{\text {put }}=80$. We suppose that the investors can exercise the puttable right after one year.

Now we take the convertible bond under time-varying volatility interest rate binary tree to explain its pricing process. Take four points A, B, C, and D in pricing tree of Figure 4 into consideration; among them, C, D are at the end of period, $4, \mathrm{~B}$ are at the end of period 3 , and $\mathrm{A}$ is at 
TABLE 1: Constant volatility interest rate parameters.

\begin{tabular}{|c|c|c|c|c|c|c|c|c|c|c|}
\hline $\begin{array}{l}\text { Deadline } \\
\text { year(s) } \\
t\end{array}$ & $\begin{array}{c}\text { Price of } \\
\text { bonds (yuan) } \\
P(t)\end{array}$ & $\begin{array}{c}\text { Volatility of } \\
\text { short-term } \\
\text { interest rate (\%) } \\
\sigma(t)\end{array}$ & $\begin{array}{c}\text { Annual } \\
\text { profit rate of } \\
\text { bonds }(\%) \\
y(t)\end{array}$ & $\begin{array}{c}\text { 1-year } \\
\text { long-term } \\
\text { interest rate } \\
(\%) \\
f(t) \\
\end{array}$ & $\begin{array}{c}\text { Variance } \\
\sigma^{2}\left(\sum_{j=1}^{t} r(j)\right)\end{array}$ & $\begin{array}{c}\text { Sum of } \\
\text { Delta }(\%) \\
\sum_{j=1}^{t-1} \delta(j)\end{array}$ & $\begin{array}{c}\text { Delta } \\
(\%) \\
\delta(t)\end{array}$ & $\begin{array}{c}\text { Drift item } \\
\quad(\%) \\
\mu(t)\end{array}$ & $\begin{array}{c}\text { Sum of drift } \\
\text { items }(\%) \\
\sum_{j=0}^{t-1} \mu(j)\end{array}$ & $\begin{array}{c}\text { Expectation } \\
(\%) \\
E_{0}^{Q}[r(t)]\end{array}$ \\
\hline 0 & & 1.6 & & 6.145 & & 0.0128 & 0.0128 & 0.4548 & 0.4548 & 6.145 \\
\hline 1 & 0.9404 & & 6.145 & 6.587 & 0.000256 & 0.0512 & 0.0384 & 1.2304 & 1.6852 & 6.5998 \\
\hline 2 & 0.8805 & & 6.366 & 7.779 & 0.00128 & 0.1152 & 0.064 & -0.414 & 1.2712 & 7.8302 \\
\hline 3 & 0.8146 & & 6.837 & 7.301 & 0.003584 & 0.2048 & 0.0896 & & & 7.4162 \\
\hline 4 & 0.7572 & & 6.953 & & 0.00768 & & & & & \\
\hline
\end{tabular}

TABLE 2: Time-varying volatility interest rate parameters.

\begin{tabular}{|c|c|c|c|c|c|c|c|c|c|c|}
\hline $\begin{array}{l}\text { Deadline } \\
\text { year(s) } \\
t\end{array}$ & $\begin{array}{c}\text { Price of } \\
\text { bonds (yuan) } \\
P(t)\end{array}$ & $\begin{array}{c}\text { Volatility of } \\
\text { short-term } \\
\text { interest rate }(\%) \\
\sigma(t)\end{array}$ & $\begin{array}{c}\text { Annual } \\
\text { profit rate of } \\
\text { bonds (\%) } \\
y(t)\end{array}$ & $\begin{array}{c}\text { 1-year } \\
\text { long-term } \\
\text { interest rate } \\
\text { (\%) } f(t)\end{array}$ & $\begin{array}{c}\text { Variance } \\
\sigma^{2}\left(\sum_{j=1}^{t} r(j)\right)\end{array}$ & $\begin{array}{c}\text { Sum of } \\
\text { Delta }(\%) \\
\sum_{j=1}^{t-1} \delta(j)\end{array}$ & $\begin{array}{c}\text { Delta } \\
(\%) \\
\delta(t)\end{array}$ & $\begin{array}{c}\text { Drift item } \\
\qquad(\%) \\
\mu(t)\end{array}$ & $\begin{array}{c}\text { Sum of drift } \\
\text { items (\%) } \\
\sum_{j=0}^{t-1} \mu(j)\end{array}$ & $\begin{array}{c}\text { Expectation } \\
(\%) \\
E_{0}^{Q}[r(t)]\end{array}$ \\
\hline 0 & & 1.6 & & 6.145 & & 0.0128 & 0.0128 & 0.4548 & 0.4548 & 6.145 \\
\hline 1 & 0.9404 & 1.5 & 6.145 & 6.587 & 0.000256 & 0.0465 & 0.0337 & 1.2257 & 1.6805 & 6.5998 \\
\hline 2 & 0.8805 & 1.2 & 6.366 & 7.779 & 0.001186 & 0.0768 & 0.0303 & -0.4477 & 1.2328 & 7.8255 \\
\hline 3 & 0.8146 & 1.3 & 6.837 & 7.301 & 0.002722 & 0.1404 & 0.0636 & & & 7.3778 \\
\hline 4 & 0.7572 & & 6.953 & & 0.00553 & & & & & \\
\hline
\end{tabular}

TABle 3: Default rate of corporate bonds under constant volatility interest rate model.

\begin{tabular}{lcccc}
\hline Time period & $0-1\left(\lambda_{1}\right)$ & $1-2\left(\lambda_{2}\right)$ & $2-3\left(\lambda_{3}\right)$ & $3-4\left(\lambda_{4}\right)$ \\
\hline Default rate & 0.0271 & 0.0394 & 0.0342 & 0.0737 \\
\hline
\end{tabular}

TABLE 4: Default rate of corporate bonds under time-varying volatility interest rate model.

\begin{tabular}{lcccc}
\hline Time period & $0-1\left(\lambda_{1}\right)$ & $1-2\left(\lambda_{2}\right)$ & $2-3\left(\lambda_{3}\right)$ & $3-4\left(\lambda_{4}\right)$ \\
\hline Default rate & 0.0271 & 0.0389 & 0.0348 & 0.0734 \\
\hline
\end{tabular}

the end of period 2. At point $\mathrm{C}$, as the convertible value is 108.57 that is larger than the face value 100 , the value of convertible bond is 108.57 , while the bonds value is 0 , so write it as [108.57,0]; the first number means the equity value and the second number means the bonds value. In the same way, we can get the convertible value of $\mathrm{D}$ point that can be written as $[0,100]$. And the up probability of $B$ point is $p_{r(3) u u d}\left(1-\lambda_{4}\right)=0.8027 \times(1-0.0734)=0.7438$. At the same way, the down probability is 0.1828 . Then the equity value of $B$ point is $108.57 \times 0.7438 \times e^{-0.08578}=74.12$. The bonds value of B point is $(45 \times 0.0734+100 \times 0.1828) e^{-0.08578}=19.81$. Then the holding value $E V_{B}$ is 93.93. And the convertible value at $B$ point is 90.24 , so the value of convertible bonds in $B$ point is

$$
\begin{aligned}
V_{B} & =\max \left[\min \left(E V_{B}, V_{\text {call }}\right), V_{B}^{\text {con }}, V_{\text {put }}\right] \\
& =\max [\min (93.93,108), 90.24,80]=93.93,
\end{aligned}
$$

written as $[74.12,19.81]$.
In the same way, we can calculate the value of other three branch points E, F, and G at the end of period 3 that are $[125.51,2.96],[125.51,3.03]$, and $[79.00,13.22]$. So the equity value at $\mathrm{A}$ point is

$$
\begin{aligned}
& (125.51 \times 0.3607+125.51 \times 0.3607+79.00 \\
& \times 0.1219+74.12 \times 0.1219) \times e^{-0.10826}=98.00 .
\end{aligned}
$$

The bonds value at A point is

$$
\begin{aligned}
& (45 \times 0.0348+2.96 \times 0.3607+3.03 \times 0.3607 \\
& \quad+13.22 \times 0.1219+19.81 \times 0.1219) e^{-0.10826}=6.96
\end{aligned}
$$

Then the holding value $E V_{A}$ is 104.96. And the convertible value at A point is 108.57, so the value of convertible bonds in A point is

$$
\begin{aligned}
V_{A} & =\max \left[\min \left(E V_{A}, V_{\text {call }}\right), V_{A}^{\text {con }}, V_{\text {put }}\right] \\
& =\max [\min (104.96,108), 108.57,80]=108.57,
\end{aligned}
$$

written as $[108.57,0]$. The other branch point in the pricing binary tree of convertible bonds can be got in the same way.

At last, under time-varying volatility interest rate binary tree model, we can get the price of convertible bond which contains credit risk that is 79.32 at the time of $t=0$. Similarly, under constant volatility interest rate binary tree model, we can get the price of convertible bond which contains credit risk that is 78.52 at the time of $t=0$; this is less than the former. 


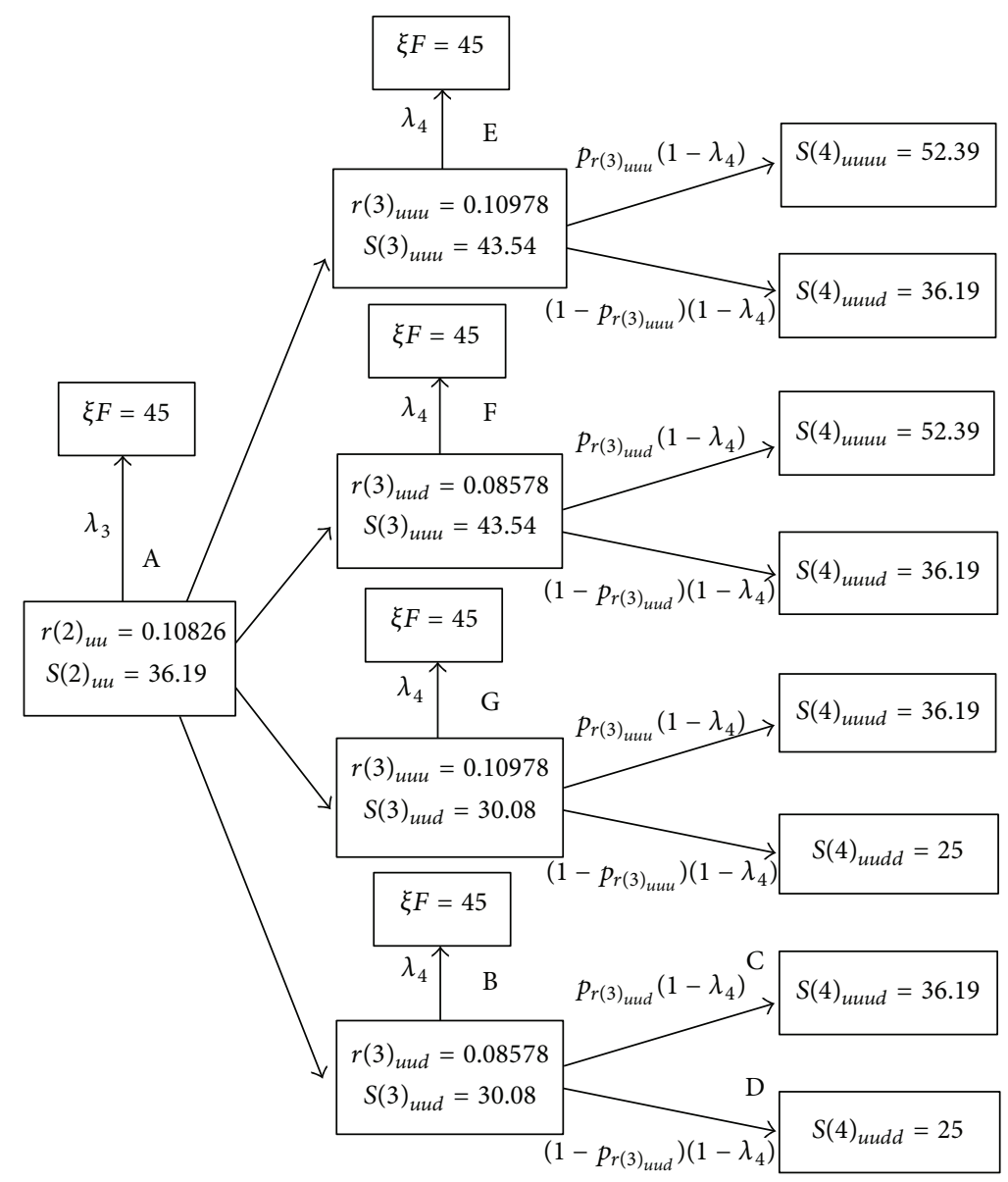

FIGURE 4: Constructing pricing tree under time-varying volatility interest rate model.

\section{Conclusions}

Binary tree method is a classical pricing method, by constructing the binary tree of state variable to describe the possible paths of state variable in the duration of contingent claims and then to make pricing research. Binary tree method can effectively solve the path-dependent options pricing, intuitive and easy to operate. As the embedded options in the convertible bonds are all American options, binary tree method becomes one of the main pricing methods of convertible bonds. Interest rate is the main factor which impacts the price of convertible bonds; the description of its binary tree model is the main problem of convertible bonds pricing. This paper adopts constant volatility and timevarying volatility binary tree model to describe interest rates and further consider the impact of stock dividends and credit risk to the price of convertible bonds, adopt default rate and recovery rate to describe the credit risk, and get the twofactor binary tree model with credit risk added. Based on this, we make a numerical example and get the convertible bonds pricing result under the stock prices obeying CRR model and the constant and time-varying volatility interest rate binary tree model. The model can be popularized to the pricing of convertible bonds with more complex provisions and other financial derivatives such as bond options, catastrophe bonds, and mortgage-backed security.

\section{Acknowledgments}

This work was supported in part by the Natural Science Foundation of China (no. 71071166, no. 71201013, and no. 70921001) and the Ministry of Education of Humanities and Social Science Project of China (no. 12YJC630118).

\section{References}

[1] M. Ammann, A. Kind, and C. Wilde, "Simulation-based pricing of convertible bonds," Journal of Empirical Finance, vol. 15, no. 2, pp. 310-331, 2008.

[2] V. S. Guzhva, K. Beltsova, and V. V. Golubev, "Market undervaluation of risky convertible offerings: evidence from the airline industry," Journal of Economics and Finance, vol. 34, no. 1, pp. 30-45, 2010.

[3] T. Kimura and T. Shinohara, "Monte Carlo analysis of convertible bonds with reset clauses," European Journal of Operational Research, vol. 168, no. 2, pp. 301-310, 2006.

[4] J. Yang, Y. Choi, S. Li, and J. Yu, "A note on 'Monte Carlo analysis of convertible bonds with reset clause', European Journal of Operational Research, vol. 200, no. 3, pp. 924-925, 2010.

[5] M. A. Siddiqi, "Investigating the effectiveness of convertible bonds in reducing agency costs: a Monte-Carlo approach," Quarterly Review of Economics and Finance, vol. 49, no. 4, pp. 1360-1370, 2009. 
[6] J. C. Cox, S. A. Ross, and M. Rubinstein, "Option pricing: a simplified approach," Journal of Financial Economics, vol. 7, no. 3, pp. 229-263, 1979.

[7] W. Cheung and L. Nelken, "Costing the converts," RISK, vol. 7, pp. 47-49, 1994.

[8] P. Carayannopoulos and M. Kalimipalli, "Convertible bonds prices and inherent biases," Working Paper, Wilfrid Laurier University, 2003.

[9] M. W. Hung and J. Y. Wang, "Pricing convertible bonds subject to default risk," The Journal of Derivatives, vol. 10, pp. 75-87, 2002.

[10] D. R. Chambers and Q. Lu, "A tree model for pricing convertible bonds with equity, ' interest rate, and default risk", The Journal of Derivatives, vol. 14, pp. 25-46, 2007.

[11] R. Xu, "A lattice approach for pricing convertible bond asset swaps with market risk and counterparty risk," Economic Modelling, vol. 28, no. 5, pp. 2143-2153, 2011.

[12] P. Ritchken, Derivative Markets, HarperCollins College, New York, NY, USA, 1996.

[13] T. S. Y. Ho and S. B. Lee, "Term structure movements and pricing interest rate contingent claims," Journal of Finance, vol. 41, pp. 1011-1029, 1986.

[14] D. Grant and G. Vora, "Analytical implementation of the Ho and Lee model for the short interest rate," Global Finance Journal, vol. 14, no. 1, pp. 19-47, 2003.

[15] R. Jarrow and S. Turnbull, Derivative Securities, South-Western College, Cincinnati, Ohio, USA, 1996.

[16] S. Roman, Introduction to the Mathematics of Finance, Undergraduate Texts in Mathematics, Springer, New York, NY, USA, 2nd edition, 2012.

[17] J. Hull, Options, Futures, and Other Derivatives, Tsinghua University Press, 6th edition, 2009.

[18] R. A. Jarrow and S. M. Turnbull, "Pricing derivatives on financial securities subject to credit risk," Journal of Finance, vol. 50, pp. 53-85, 1995. 


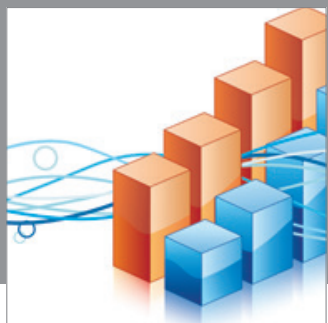

Advances in

Operations Research

mansans

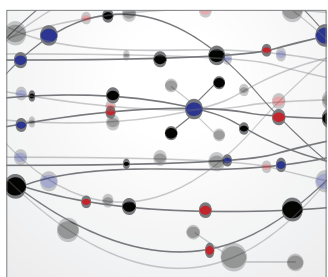

The Scientific World Journal
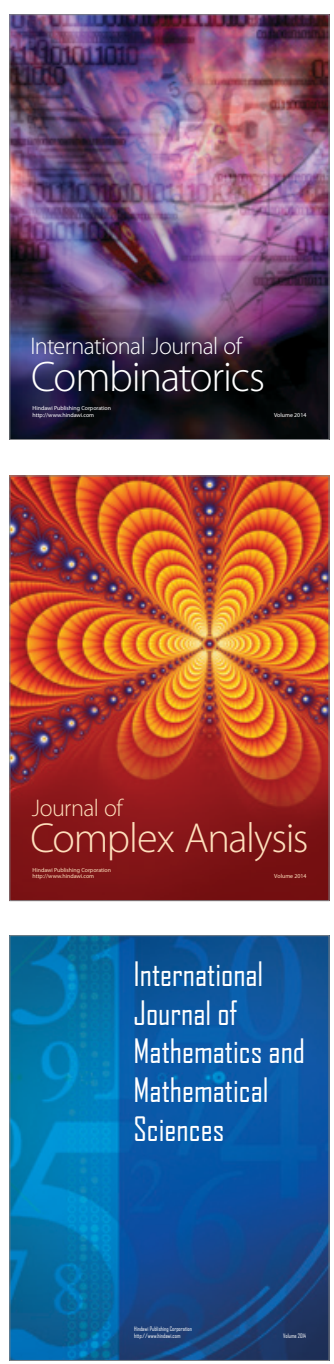
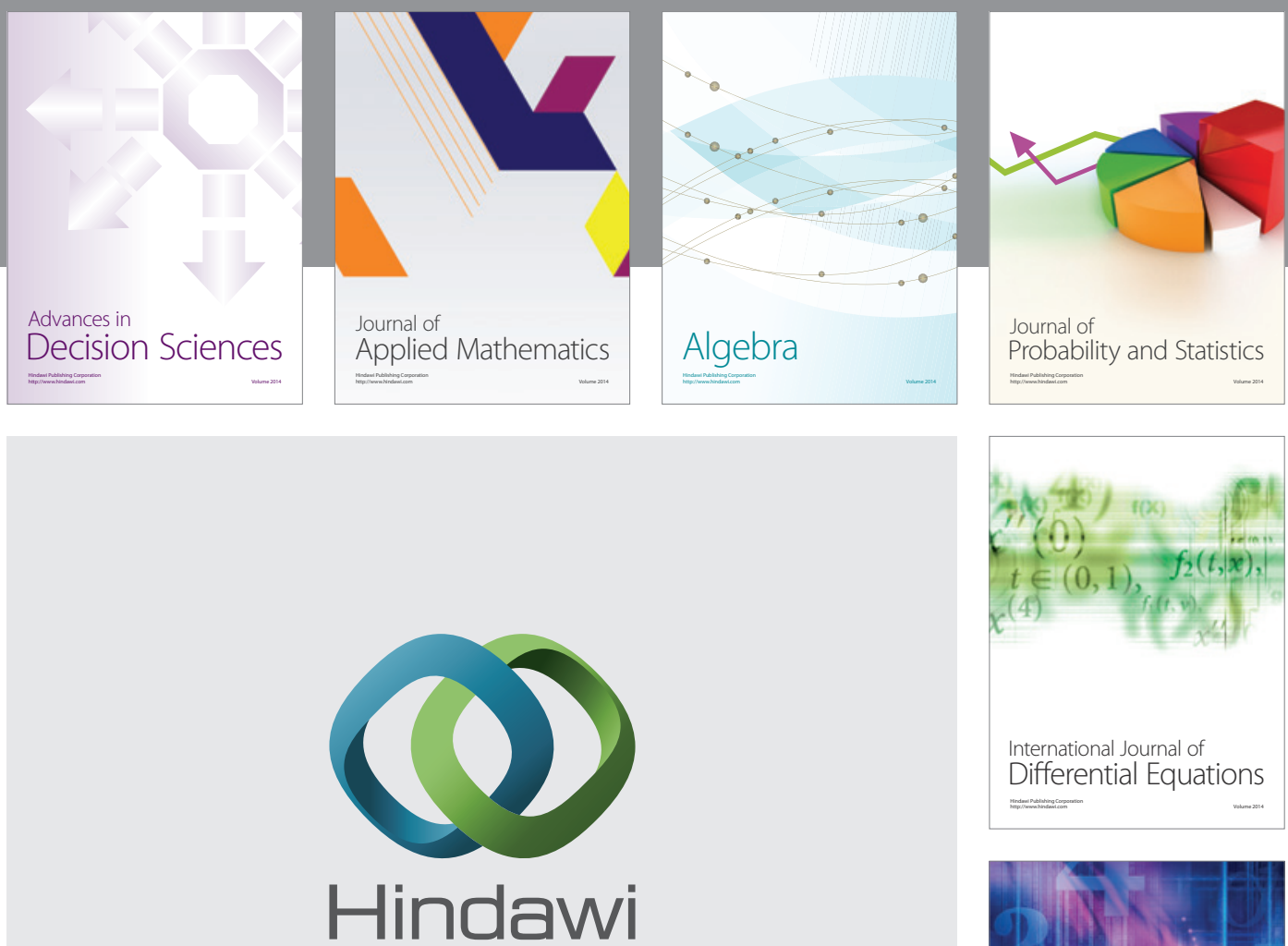

Submit your manuscripts at http://www.hindawi.com
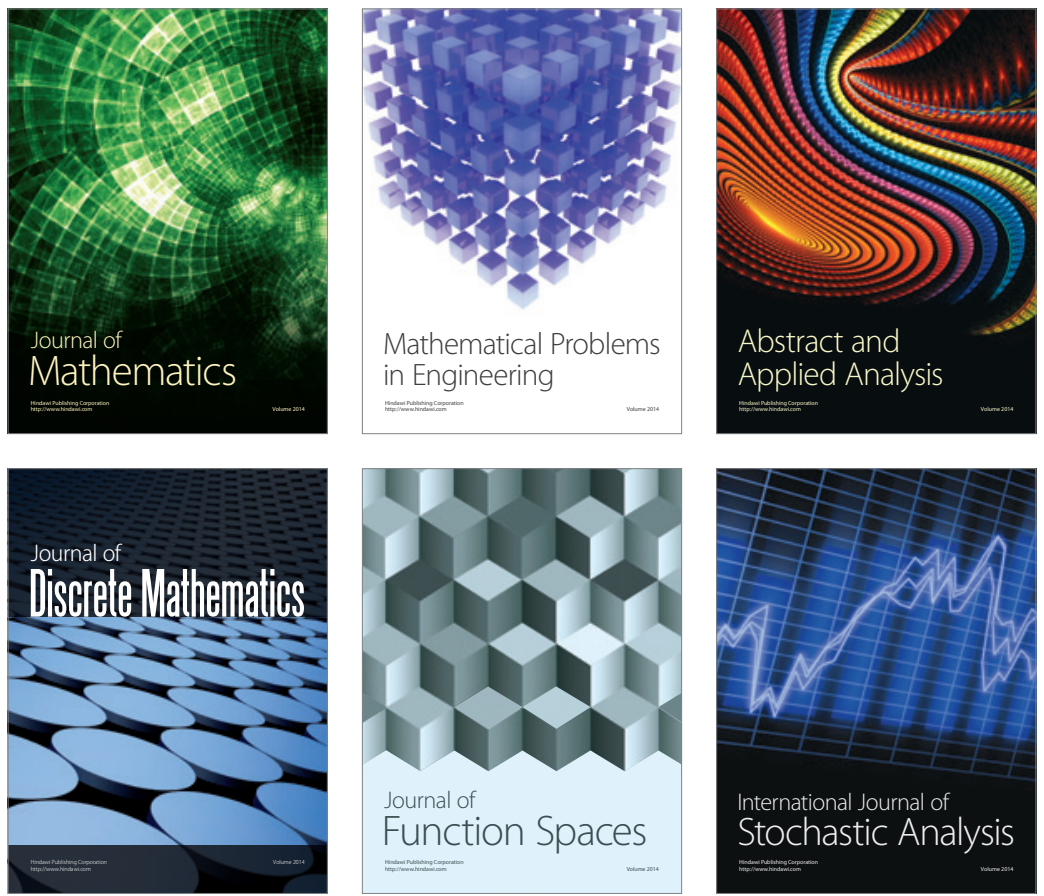

Journal of

Function Spaces

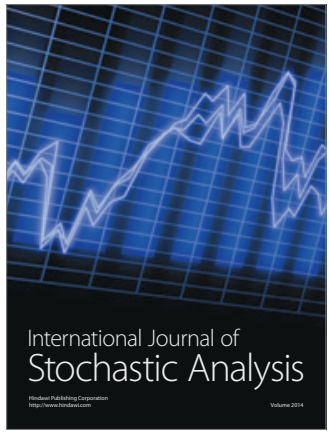

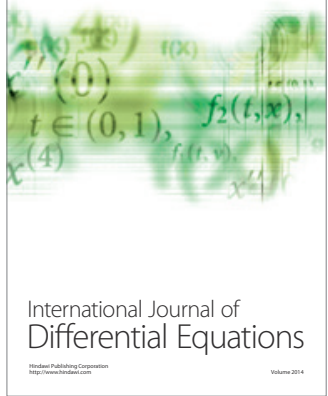
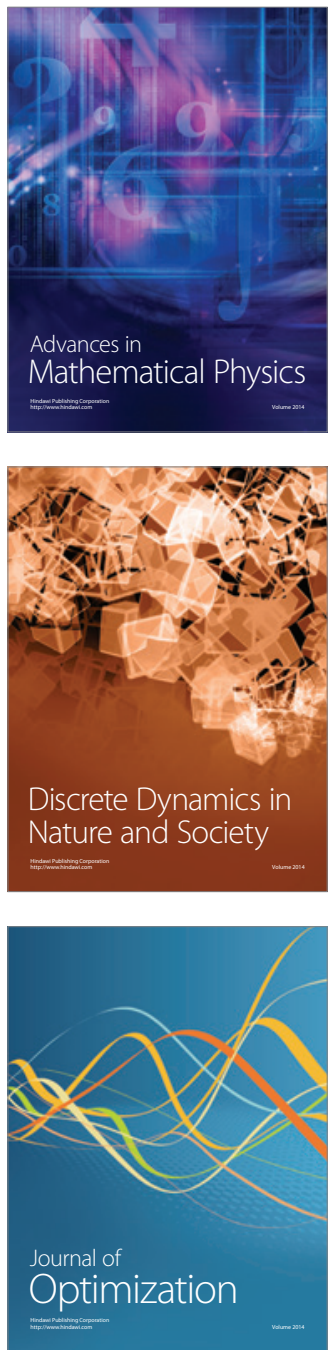